\title{
VARIA
}

\section{DOS PINTURAS DE DENIS CALVAERT IDENTIFICADAS EN LOS FONDOS DEL MUSEO DEL PRADO}

Atendiendo a razones de estilo este estudio da a conocer dos pinturas inéditas de Denis Calvaert entre los fondos del museo del Prado. Pintor flamenco poco conocido en España por la escueta obra que aquí se conserva, y por su fuerte influencia italiana que ha hecho que muchas de sus obras hayan estado atribuidas a esta última escuela. Palabras clave: Denis Calvaert; Pintura flamenca; Siglo XVI.

Based on stylistic considerations, this study attributes two unpublished paintings in the Prado Museum to Denis Calvaert. This Flemish artist is not well known in Spain due to the scarcity of his works and because of a strong Italian stylistic influence, which has contributed to the incorrect attribution of his paintings.

Key words: Denis Calvaert; Flemish painting; $16^{\text {th }}$ Century.

El museo del Prado tiene depositado en el Consejo de Estado desde $1883^{1}$, un bello lienzo representando el tema de Abraham visitado por los tres ángeles de autor desconocido $(147 \times$ $161 \mathrm{~cm}$.) (n. ${ }^{\circ} 3.329$ ) (fig. 1). Los inventarios y catálogos del museo lo consideran de escuela italiana del siglo XVI desde sus primeros asientos. Entra a formar parte de las colecciones de la pinacoteca madrileña en 1858, y José de Madrazo lo inscribe con el número 397 dentro de la escuela florentina del siglo XVI: "Abraham visitado por los ángeles. El santo Patriarca recibe en su casa a los tres mancebos los cuales le anuncian la fecundidad de la anciana Sara. Alto 5 pies, 2 pulg, 6 lin; ancho 5 pies 8 pulg"'; en 1872 figura con el número 568 y sigue teniendo la misma consideración. Sólo se describe con mayor precisión el tema ${ }^{3}$. Estos números de inventario citados están inscritos en el lienzo, el primero en la esquina inferior izquierda con tinta roja, y el segundo a tiza en el reverso.

Abraham ocupa el centro del primer plano como protagonista y eje en torno al que se supeditan el resto de personajes. Vuelve su cabeza hacia los tres ángeles que llegan por la derecha y les invita, con el gesto de sus manos, a un pequeño refrigerio dispuesto sobre el mantel que

\footnotetext{
1 R.O. 27 de diciembre de 1883.

2 Madrazo, Pedro de, Catalogo de los cuadros del Real Museo de Pintura, Madrid, 1858, p. 98, n. ${ }^{\circ} 397$.

3 "Anónimo de escuela italiana. Escuela florentina. Abraham visitado por los tres ángeles. Alto 146, Ancho 158, Lienzo. Recibe en su tienda el santo patriarca a los tres celestiales mensajeros que le anuncian la fecundidad de la anciana Sara, y después de adorarlos, el invita a aceptar su mesa frugal, preparada al pie de una copuda encina, Sara presencia la escena desde la entrada de la tienda. Fondo: país con las montañas de la tierra de Mambre”. MADRAZO, Pedro de, Catálogo descriptivo e histórico del Museo del Prado de Madrid. Escuelas italianas y españolas, Madrid, 1872 , p. 321, n. $^{\circ} 568$.
} 


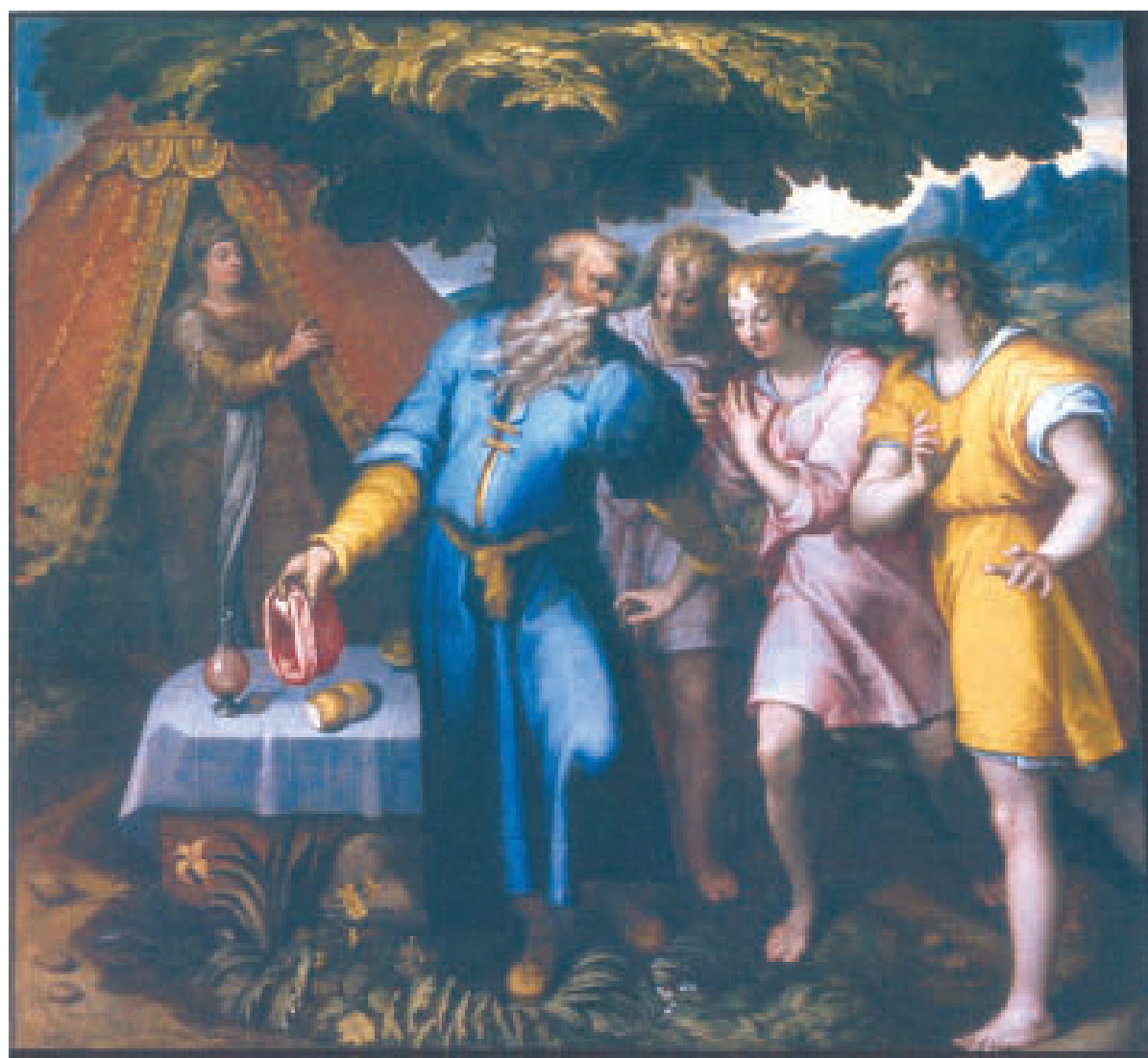

Fig. 1. Denis Calvaert, Abraham y los tres ángeles, Madrid, Museo Nacional del Prado.

cubre la tosca roca. La frondosa encina cobija este banquete de tres panes y una jarra de vino, prefiguración de la Eucaristía. Sara asoma curiosa a la puerta de la tienda del segundo plano.

La historia es narrada en el Génesis $(18,1-15)$, y tiene gran importancia como prefiguración de la Anunciación, relación de la Divinidad con el Hombre; primero con Abraham, y posteriormente a través de Jesús, y como una de las obras de Misericordia: ser hospitalario con el extranjero ${ }^{4}$. Fue un tema retomado con intención en la Contrarreforma y muy solicitado por los jesuitas ${ }^{5}$.

La monumentalidad de las figuras y el predominio de tonos saturados de añil, amarillo, rosa y malva es propia de la escuela italiana, por lo que no es extraño que se haya vinculado con esta escuela en los inventarios del museo del Prado. Pero la técnica precisa y cuidadosa con los detalles y recreación de la naturaleza, cabellos y barbas de los personajes, y la búsqueda de los sutiles efectos de la luz en el reflejo del vino sobre el mantel al atravesar el cristal de la jarra, o la luminosidad del amanecer del fondo consiguiendo un aspecto brumoso y diluido de los campos y montañas de estos últimos planos, es propia del mundo flamenco. Estas características, unidas

${ }^{4}$ RÉAU, L., Iconografía del Arte cristiano. Antiguo Testamento, 1/1, Barcelona, 1996, p. 162.

${ }^{5}$ Sobre la relación de Denis Calvaert y los jesuitas, véase: Moralejo OrTEGA, M., "Variaciones iconográficas sobre el tema de la Natividad: una inédita adoración de pastores", Archivo Español de Arte, LXXVII, 2004, pp. 312-313 y n. 18. 
a los tipos empleados para los personajes, vinculan este lienzo del museo del Prado con el trabajo de Denis Calvaert, pintor amberino asentado en Bolonia sobre los años sesenta del siglo XVI ${ }^{6}$.

El primer ángel de la derecha, visto de perfil, con la boca entreabierta y la mirada dirigida a Abraham, es un modelo que repite Calvaert en personajes femeninos: la Virgen de la Presentación en el templo de la iglesia de Santo Domingo de Bolonia; la Vigilancia, fechada en 1568, y la figura de María Magdalena del Noli me tangere de la pinacoteca nacional de la misma ciudad (fig. 2), y el ángel de la derecha del primer plano del dibujo de la Sagrada Familia con ángeles del Louvre. Muy característico del pintor son los rostros de los ángeles más secundarios de este lienzo del Prado, de ojos redondos y párpados gruesos, nariz recta, boca pequeña y dos mechones arremolinados que caen sobre la frente. Este modelo lo retoma Calvaert para algunos de los ángeles de la Asunción de la Virgen de la pinacoteca nacional de Bolonia; Virgen con el Niño y San Francisco de la colección de la Universidad Greenville, obra firmada y fechada en 1607; y Noli me tangere de la iglesia de Santa María Magdalena de Cazzano di Budrio, autógrafa y datada en 1585 (fig. 3). Esta última pintura comparte con el lienzo del Prado la indumentaria elegida para los ángeles, con túnica de media manga y cuello redondo con solapas.

La influencia de los grandes maestros italianos, que Calvaert copió con esmero como dicen sus contemporáneos ${ }^{7}$, está aquí muy presente en la figura de Abraham ${ }^{8}$. El rostro vuelto de perfil hacia los ángeles, con el ceño fruncido, llena de movimiento la larga barba de gruesos bucles, recuerda el rostro del Moisés de Miguel Ángel. Este sentido tan ornamental de realizar la barba y cabellos ondulantes de los ángeles se ve en la figura de San Sebastián de la Virgen con los santos de la iglesia de San Lucas de Bolonia que realiza Calvaert; Cristo atado a la columna de la pinacoteca nacional boloñesa, San Miguel de la iglesia de San Petronio de la misma ciudad, y San José del dibujo citado de la Sagrada Familia con ángeles del Louvre.

La posición del cuerpo del patriarca, en sentido inverso al movimiento de su rostro, dota de dinamismo esta escena, equilibrada por la prestancia tectónica del árbol sobre los protagonistas. La posición de las piernas en contraposto y los brazos en direcciones opuestas logra dar unidad a los personajes dentro de la composición, al relacionar, por medio del gesto, a los tres ángeles con el banquete a su derecha. Todo se encuadra en un esquema cerrado, definido por la figura de Sara a la izquierda, el ángel a la derecha, las ramas del árbol y la vegetación del suelo.

${ }^{6}$ Denis Calvaert nace en Amberes y entra como aprendiz en el taller de Kerstiaen van den Queckborne, en 1556, bajo cuya tutela sigue en 1558. Rombouts, Ph. \& Van Lerius, Th., De Liggeren en andere historische Archieven der Antwerpsche Sint Lucasgilde, I, Amsterdam, 1961, p. 199. Muy considerado en Bolonia, MaLvasia ya lo cita en su libro Felsina Pittrice; al igual que Lomazzo, Idea del tempio della pittura, Milan, 1590, ed. Florence, 1974, p. 395; el resto de preceptistas italianos lo vinculan con el aprendizaje de Reni y otros pintores boloñeses. Es en el siglo XX cuando aparecen las primeras monografías y artículos: MArChesinI, C., "Dionisio Calvaert", en Comune di Bologna, XIX, 10, 1932, pp. 65-67; Bergmans, S., Cataloque critique des Oeuvres du pientre Denis Calvart, Academie royale de Belgiques, Mémoires 3, Brüssel, 1931; Bergmans, S., Denis Calvart, Peintre Anversois. Fondateur de l'école bolonaise, Academié Royale de Belgiques, Mémoires 4, Brüssel, 1934. Posteriormente han salido artículos monográficos y obras colectivas de pintores trabajando en Bolonia que le destacan en especial: ANDrews, K., "The Marriage at Cana a Trio by Denys Calvaert", The Burlington Magazine, 127, 1985, p. 157; GERTZI, T., "Un dessin récenmment identifié de Denys Calvaert", Bulletin du Musee Hongrois des Beaux Arts, 65, 1985, pp. 35-42; Montella, T., "Dionisio Calvart" en Pittura bolognese del '500, II, Bologna, 1986, pp. 683-708; KLOEK, W. Th., "Calvaerts oefeningen met spiegelbeeldigheid”, Oud Holland, 107, 1, 1993, pp. 59-74; DAcos, N., "Denys Calvaert" en Fiaminghi a Roma, 1508-1608, Cat., Exp., BruxellesRome, 1995, pp. 130-132; BIANCHI, D., "I dipinti di Raffaello che adornano la loggia de'Ghigi in Tratevere", "La presenza dei modelli romani nell'attività artistica di Denis Calvaert", en Studi di storia dell'arte in onore di Denis Mahon, Mailand, 2000, pp. 27-36; Twienaus, S., Dionisio Calvaert (um 1540-1619). Die Altarwerke, Berlín, 2002.

7 Malvasia, C. C., Felsina Pittrice. Vite dei Pittori Bolognesi, 1678, ed. Brascalia, Bologna, 1971, p. 165.

8 Sobre el eclecticismo de las obras de Calvaert, tomando modelos tanto de artistas italianos como flamencos contemporáneos, grabados o apuntes que él pudo hacer, véase: KLoEK, W. Th., "Calvaerts oefeningen...", Op. cit., Oud Holland, 107, 1993, pp. 60-63, y n. 9. 


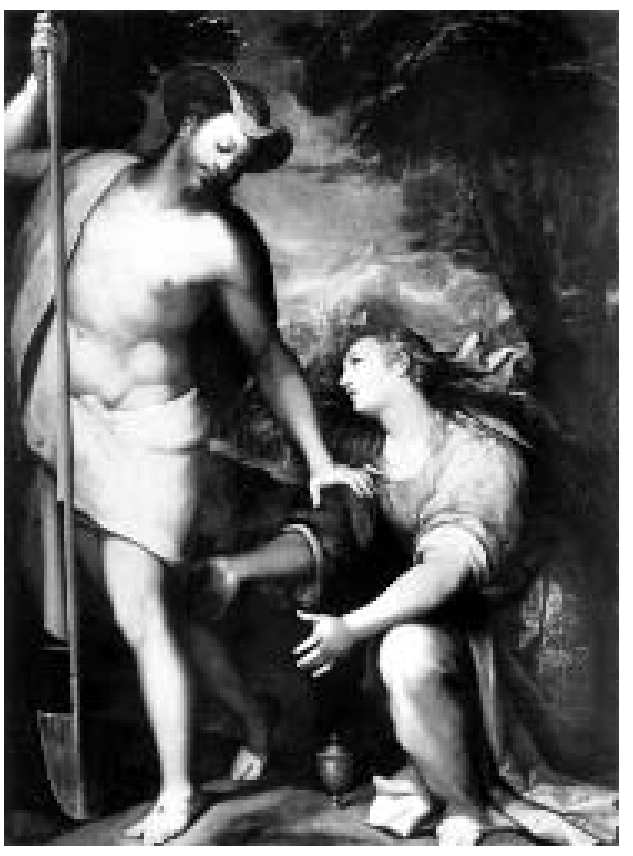

Fig. 2. Denis Calvaert, Noli me tangere, Bolonia, Pinacoteca Nacional.

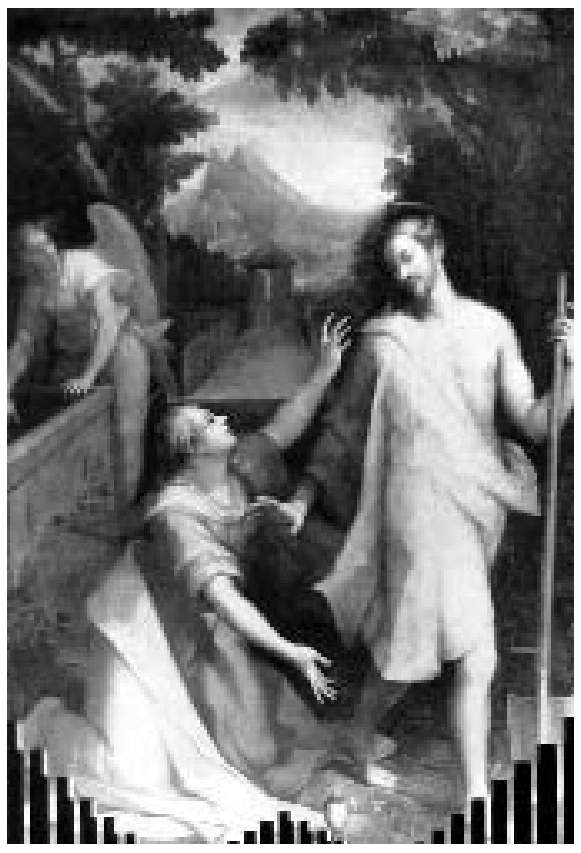

Fig. 3. Denis Calvaert, Noli me tangere, Cazzano di Budrio, Iglesia de la Magdalena.

El sentido decorativo de los elementos subsidiarios de la escena, sobretodo de la vegetación del primer plano y el follaje de la encina, se acentúa por el uso de luz que cae de la parte superior y da un sentido grueso y carnoso a las hojas. El árbol es un protagonista más de la escena como narra el Génesis: "Se apareció Yahvé en el encinar de Mambré mientras Abraham estaba sentado a la entrada de la tienda". Este gusto por las hojas carnosas es un recurso que Calvaert emplea en muchas de las obras citadas, como el Noli me tangere de la galería de Bolonia, e iglesia de Santa María Magdalena de Cazzano di Budrio, ya citadas; Virgen con San Francisco y Santo Domingo del Staatlichemuseum de Dresde, fechada en 1598; y sobretodo en la Estigmatización de San Francisco de la iglesia del Corpus Domini de Bolonia. Incluso las pequeñas flores del primer plano y vegetación del suelo se repiten en sus composiciones. En este lienzo del Prado el aspecto agreste de las hierbas y plantas se genera por la pincelada larga y llena de empasto con que realiza Calvaert cada una de las hojas, combinando los verdes con blancos y ocres oscuros.

Valorando las características señaladas de la pintura del museo del Prado, y su relación con las obras fechadas de Calvaert, se puede relacionar con su etapa en Bolonia, entre 1570 y 1590 , donde aún se observa cierta pervivencia de los modelos de Martin de Vos en las figuras.

\footnotetext{
9 Esta influencia del maestro de Amberes pudo haber sido tanto por grabados como de forma directa de sus pinturas. No sólo por el gusto monumental de sus figuras en primer plano sino también por estructurar la escena en torno a un eje central, como era habitual en obras de Martin de Vos, usando el árbol como elemento distribuidor de los personajes. Como hace en el dibujo de Moisés liberando a su pueblo de Egipto, firmado por el pintor en 1580. [De Maigret, París, 23, marzo, 2007, n. ${ }^{\circ}$ 60]; o los grabados de Adán y Eva; y la Alegoría de la Paciencia. Sobre el uso de los grabados ya habla Kloek al indicar que Calvaert fomenta el estudio de los grabados entre sus alumnos. KLOEK, W. Th., “Calvaerts oefeningen...", Op. cit., Oud Holland, 107, 1993, pp. 59-74.
} 


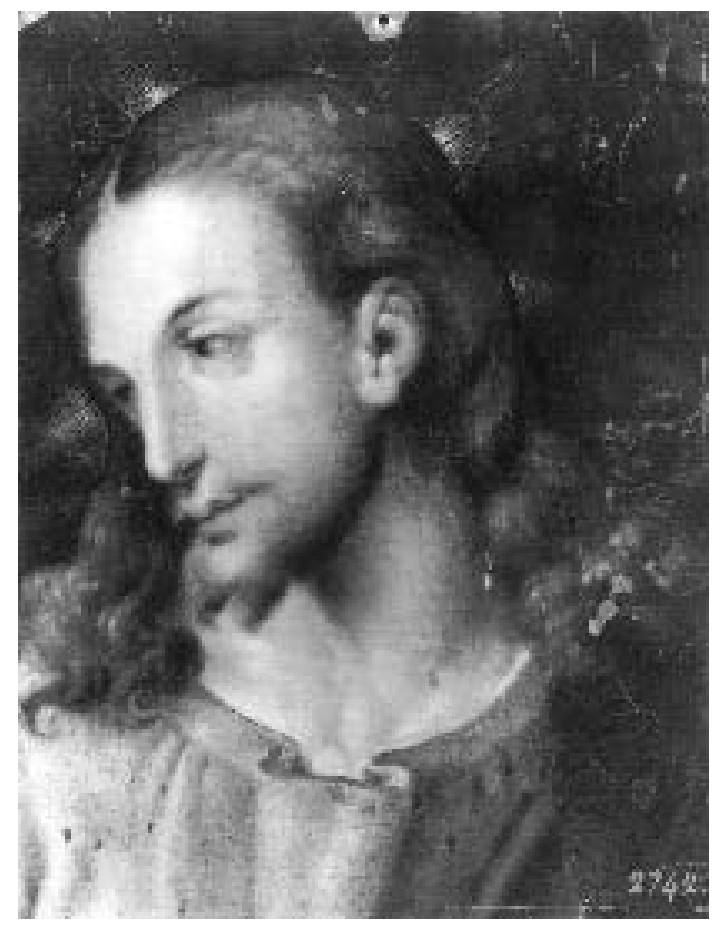

Fig. 4. Denis Calvaert, Cabeza del Salvador, Madrid, Museo Nacional del Prado.

No hay constancia de si la pintura fue un encargo. No sería de extrañar, tanto por el tema, muy vinculado con las posturas contrarreformitas por su prefiguración de la Anunciación, la Eucaristía, y la importancia de las obras de misericordia; como por la relación conocida de Calvaert con los jesuitas ya mencionada.

Según el inventario del museo del Prado la pintura procede de las colecciones reales ${ }^{10}$, pero el rastreo de la pintura dentro de los inventarios desde el siglo XVII no ha dado buen resultado. Quizá por haber sido alguna incorporación tardía, o por haber estado en alguna residencia real de la que no han llegado inventarios, hasta ahora.

La otra pintura que se identifica entre los fondos del museo del Prado de mano del maestro Calvaert es un pequeño busto de Cristo en cobre $^{11}$ (n. ${ }^{0} 3.831$ ) (fig. 4). Posiblemente en un primer momento formara parte de una composición mayor por el extraño encuadre que presenta, y el lamentable estado de conservación, lleno de pérdidas de la capa pictórica y suciedad acumulada por el tiempo.

Este sereno rostro de Cristo se vuelve de perfil hacia la izquierda. Un suave esfumatto suaviza los contornos y envuelve el busto en una sutil atmósfera, propia de la delicadeza y suavidad que destilan las pinturas de Denis Calvaert. Esta tipología de rostro con el cabello ondulado dividido en dos en el centro de la cabeza, cayendo un mechón sobre el rostro derecho, y el resto recogido tras la oreja izquierda, despejando su perfil, nariz recta enmarcando los ojos de grueso párpado y cejas finas y arqueadas, es similar al que emplea el pintor para el mismo personaje en el Noli me tangere de la iglesia de Santa María Magdalena en Cazzano di Budrio, obra citada líneas atrás; y en sentido invertido para el Jesús de la Resurrección de Lázaro del monasterio benedictino de Seedorf, obra firmada y datada en 1598.

La barba rala encuadra el mentón y en la barbilla se abren dos pequeños mechones a ambos lados. El sentido decorativo se deja sólo para la túnica con el grácil pliegue en torno al cuello y el nimbo de rayos enmarcando la cabeza sobre el fondo oscuro. Esta fórmula de nimbo va a ser la habitual en Calvaert a finales del siglo XVI y primeros años del XVII, como se observa, además de en las obras citadas, en la Flagelación de la pinacoteca nacional de Bologna (n. $\left.{ }^{\circ} 46\right)$, y Santa Cena de la iglesia de Santa María y San Gregorio Magno en Montone, obra de 1611.

Procedente de las colecciones reales, la primera mención segura de la pintura es ya en su entrada en los fondos del museo en 1857 como obra de escuela flamenca ${ }^{12}$. Sin embargo, al igual que el lienzo de Abraham visitado por los tres ángeles, no se ha podido localizar en los catálogos reales de los siglos precedentes.

\footnotetext{
${ }^{10}$ Inventarios de pinturas. Museo del Prado. Colección Real, I, Madrid, 1993, n. ${ }^{\circ} 397$.

$1127 \times 22 \mathrm{~cm}$.

${ }^{12}$ Inventarios de pinturas. Museo del Prado..., Op. cit., I, n. ${ }^{\circ} 2.742$.
} 
Estas dos obras vienen a engrosar el catálogo de pinturas de Denis Calvaert, pintor muy poco representado en España hasta el momento ${ }^{13}$. A quien Bergmans ya destaca como "pintor de primer orden que ilumina con especial intensidad la historia de la pintura belga del siglo XVI"14.

\section{Ana DiéGuez RodríGuez} Instituto Moll

13 Ollero Butler, J., "Algunas novedades acerca de la pintura flamenca del siglo XVI en España. Pieter de White y Denis Calvaert", Annuario del departamento de Historia y Teoria del Arte, 2, 1991, pp. 79-82.

14 Bergmas, S., Catalogue critique des oeuvres..., Op. cit., 1931, p. 6. 